\title{
Increased expression of amyloid precursor protein promotes proliferation and migration of AML1/ETO-positive leukemia cells and can be inhibited by panobinostat
}

\author{
C. L. WANG ${ }^{1}$, B. J. DING ${ }^{1}$, L. JIANG ${ }^{1}$, C. X. YIN ${ }^{1}$, Q. X. ZHONG ${ }^{1,2}$, G. P. YU ${ }^{1}$, X. D. LI' ${ }^{1}$, F. Y. MENG ${ }^{1,2, *}$ \\ ${ }^{1}$ Department of Hematology, Nanfang Hospital, Southern Medical University, Guangzhou, China; ${ }^{2}$ Department of Hematology, Kanghua \\ Hospital, Dongguan, Guangdong, China \\ ${ }^{*}$ Correspondence: drmengfy@163.com
}

Received February 25, 2015 / Accepted June 17, 2015

\begin{abstract}
Amyloid precursor protein (APP) is a highly conserved integral membrane protein extensively expressed in various types of cells. Previously we found that overexpression of APP in patients with AML1/ETO-positive acute myeloid leukemia (AML) associated with a higher incidence of extramedullary infiltrationin and indicate a poor prognosis. In this study, we attempted to define the roles of APP in AML1/ETO-positive leukemia cells. Western blotting and qRT-PCR analysis showed that protein levels of APP are significantly higher in Kasumi-1, a t(8;21)/ AML1/ETO-positive M2-type AML cell line. Stable knockdown of APP by lentivirus-based RNA interference (RNAi) dramatically impaired colony-formation and migration ability of Kasumi-1 cells, whereas APP knockdown had very little effect on cell viability, apoptosis, cell cycle and differentiation. We further explored whether the pan-histone deacetylase inhibitor panobinostat could deplete the protein levels of APP in Kasumi-1 cells. Treatment with panobinostat caused depletion of APP in Kasumi-1 cells. These findings indicate that overexpression of APP is involved in promoting proliferation and migration of AML1/ETO-positive leukemia cells and can be inhibited by panobinostat, which provide an attractive prospect for treatment of AML1/ETO-positive AML.
\end{abstract}

Key words: APP, Kasumi-1, AML1/ETO, panobinostat

Acute myeloid leukemia (AML) with $\mathrm{t}(8 ; 21)(\mathrm{q} 22 ; \mathrm{q} 22)$ is a specific subtype, and is frequently associated with M2 subtype according to the French-American-British (FAB) classification. The $t(8 ; 21)$ (q22; 22$)$ involves the AML1 gene on chromosome 21 and the ETO gene on chromosome 8 generating the AML1/ETO fusion gene. AML with AML1/ ETO-positive is generally considered as a favorable prognosis particularly with high-dose cytosine arabinoside (Ara-C) consolidation chemotherapy. However, the treatment outcomes are not satisfactory for a high relapse rate within one year about $30 \%$ or more[1-2]. As for the assessment of prognosis of AML patients with AML1/ETO-positive, many other elements including additional chromosomal aberrations, individual genes mutations, and clinical course should be considered.

Amyloid precursor protein (APP) is a highly evolutionary conserved protein. The gene for human APP is on chromosome $21 \mathrm{q} 21.3$ and encode a type I integral membrane protein.
APP can participate in transmembrane signaling events due to its highly conserved extracellular and intracellular domains, which plays important roles in many physiological processes [3-7]. Many recent studies have indicated that APP is overexpressed commonly in solid tumors and mainly involved in promoting proliferation of tumor cells, including oral squamous cell carcinoma[8], pancreatic cancer cells[9], parathyroid tumor[10], and breast cancer[11]. APP was also found significantly higher in AML with abnormal chromosome 21 compared to a control group of AML with normal cytogenetics using oligonucleotide arrays[12]. Our previous study found that overexpression of APP in patients with AML1/ETO-positive AML has a much higher incidence of extramedullary infiltration than that in low expression levels of APP[13]. However, the function of APP in AML1/ETOpositive leukemia cells remain elusive.

In this study, we examined the roles of APP in AML1/ ETO-positive leukemia cells via an RNA-interference (RNAi) 
lentivirus system in human AML-M2b cell line Kasumi-1 carrying AML1/ETO fusion gene. As for the important role of overexpression of APP in various of human malignancies, finding drugs that inhibiting expression levels of APP could have important implications for cancer therapy. The panhistone deaetylase inhibitors panobinostat (PS, also known as LBH589) is a novel HDACi that inhibits multiple HDAC classes, exerting potent anti-cancer effects in hematological malignancies[14-17], which aroused to be focused on deplete expression levels of APP.

\section{Materials and methods}

Cell culture and shRNA lentiviral transduction. Human AML cell lines HL60 and K562 were obtained from the Cell Bank of Chinese Academy of Sciences (Shanghai, China), and cultured in Roswell Park Memorial Institute (RMPI) 1640 medium, supplemented with $10 \%$ fatal bovine serum (FBS) (Gibco, Grand Island, New York, USA) and 1\% penicillin/ streptomycin $(100 \mu \mathrm{g} / \mathrm{mL})$. AML-M2b cell line Kasumi-1, with characteristic $\mathrm{t}(8 ; 21)$ (q22;q22) translocation and AML1/ ETO-positive, were maintained in 20\% FBS and 1\% penicillin/ streptomycin. All cells were incubated at $37^{\circ} \mathrm{C}$ in a humidified atmosphere containing $5 \% \mathrm{CO}_{2}$ saturation.

Real-time quantitative PCR. Total RNA was extracted using TRIzol reagent ((invitrogen, Carlsbad, CA, USA). Purified RNA was quantitated and synthesized to cDNAs using PrimerScript RT Reagent Kit (TaKaRa, Kyoto, Japan) according to the manufacturer's protocol. Real-time quantitative PCR(qRTPCR) was performed on 7500 FAST Real-Time PCR System (Applied Biosystems, Foster City, CA, USA) using SYBR Green Master Mix (TaKaRa, Kyoto, Japan) for APP. The forward and reverse primers of APP were 5'-TGGCCCTGGAGAACTACATC-3' and 5'-AATCACACGGAGGTGTGTCA-3'. $\beta$-actin was used normalize relative expression of the mRNA. Relative gene expression levels were analyzed using $2^{-\Delta \mathrm{Ct}}$ or $2^{-\Delta \Delta \mathrm{Ct}}$ method.

Western blotting. Proteins were prepared and quantified. Fifty micrograms of total protein were separated on $10 \%$ sodium dodecyl sulfate-polyacrylamide gel electrophoresis (SDS-PAGE) and transferred to a polyvinylidene difluoride (PVDF) membrane. Proteins were probed overnight at $4^{\circ} \mathrm{C}$ with rabbit anti-APP monoclonal antibody used at 1:1,000 dilution (Santa Cruz, CA, USA) and rabbit anti-GAPDH monoclonal antibody used at 1:2000 dilution (Beyotime, Shanghai, China). Blots were detected with a chemiluminescent substrate enhanced chemiluminescent (ECL) kit (Millipore, Boston, Massachusetts, USA). Densitometry was performed using Image-Pro Plus 6.0 (Media Cybernetics, Rockville, Maryland, USA).

shRNA lentiviral transduction. The small interference RNA (siRNA) against APP was 5'-CATCTTTGACCGAAACGAA-3', and the sequence of 5'-TTCTCCGAACGTGTCACGT-3' was set as negative control siRNA. The Short hairpin RNAs (shRNAs) designed directly from siRNA sequences, and then were packaged into lentivirus particles by Shanghai Genechem (Shanghai, China). After Kasumi-1 cells were transduced with APP shRNA (shAPP) or control non-silencing shRNA (shCon) lentivirus particles, green fluorescent protein (GFP) positive cells were separated by BD FACSAria III cell sorter (BD Biosciences, New Jersey, USA) and were incubated expendably.

Cell viability analysis. Endogenous APP knockdown on the viability of Kasumi-1 Cells was determined using Cell Counting Kit-8 (CCK-8) Dojindo, Kumamoto, Japan). Cells $\left(5 \times 10^{4}\right.$ cells $\left./ \mathrm{mL}\right)$ were seeded into 96 -well plates and incubated for 24,48 and 72 hours, respectively. CCK-8 solution was added into the wells and incubated for 4 hours. Then, the optical density (OD) was quantified at $450 \mathrm{~nm}$ wavelength using a microplate reader (Bio-Rad 680, Hercules, CA, USA).

Colony-formation assay. The proliferation effect of APP gene knockdown on Kasumi-1 cells was assessed by colonyformation assay. Treated and untreated cells in logarithmic growth phase were collected and washed twice with 1640 medium, and approximately 5000 cells were plated in methylcellulose complete StemCult (Shanghai, China) and cultured for 14 days at $37^{\circ} \mathrm{C}$ in a humidified atmosphere containing 5\% $\mathrm{CO}_{2}$ saturation. Colony growth was observed and measured with an inverted microscope.

Assessment of cell apoptosis. The percentage of apoptotic cells was analyzed using the Annexin V-APC/propidium iodide (PI) Apoptosis Detection Kit (BD Biosciences, New Jersey, USA). For apoptosis assay, cells in logarithmic growth phase were collected and stained with annexin-V-APC $(5 \mu \mathrm{L})$ for $30 \mathrm{~min}$ at $4^{\circ} \mathrm{C}$, then washed once with $1 \times \mathrm{PBS}$ and stained with PI $(5 \mu \mathrm{L})$ for $20 \mathrm{~min}$ at room temperature. The flow cytometric analysis was performed using BD FACSCanto II flow cytometer (BD Biosciences, New Jersey, USA) for the detection of apoptotic cells.

Cell-cycle and differentiation analysis. Cells were harvested and washed twice with PBS and fixed in $75 \%$ cold ethanol at $4^{\circ} \mathrm{C}$ overnight. Fixed cells were washed twice with PBS and stained with PI at a final concentration of $50 \mu \mathrm{g} / \mathrm{mL}$ for 15 minutes at $37^{\circ} \mathrm{C}$, and the ribonuclease A were added to degrade RNAs. Cell cycle was detected by flow cytometer with a $488 \mathrm{~nm}$ laser and analyzed with ModFit 3.0 (Verity Software House, USA). The percentage of differentiated cells was determined using CD11b-PE antibody(BD Biosciences, USA). For CD11b-PE staining, cells were harvested and resuspended in $100 \mu \mathrm{L}$ of PBS, then $5 \mu \mathrm{L}$ PE-conjugated anti-CD11b antibody was added and incubated at room temperature for $20 \mathrm{~min}$. The percentage of CD11b-expression cells was determined by flow cytometry.

Transwell migration assay. Cell migration assay was performed in transwell chambers (Corning, NY, USA) with $8 \mu \mathrm{m}$ pore size polycarbonate filter. Kasumi- 1 cells $\left(3 \times 10^{5}\right.$ cells/well) were seeded onto the upper chamber in $200 \mu \mathrm{l}$ of RPMI 1640 suspended with $0.1 \%$ bovine serum albumin, and $500 \mu$ of RPMI 1640 supplemented with 20\% FBS was added into the lower chamber. After incubated for 18 hours, migrated cells 
A

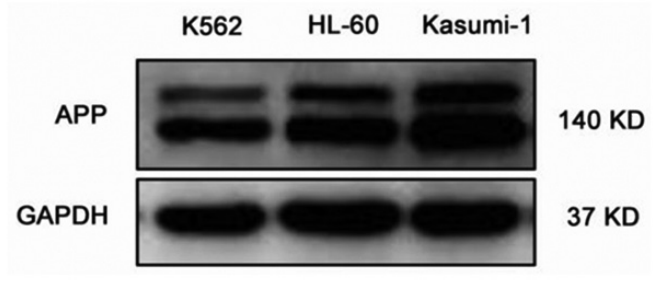

B

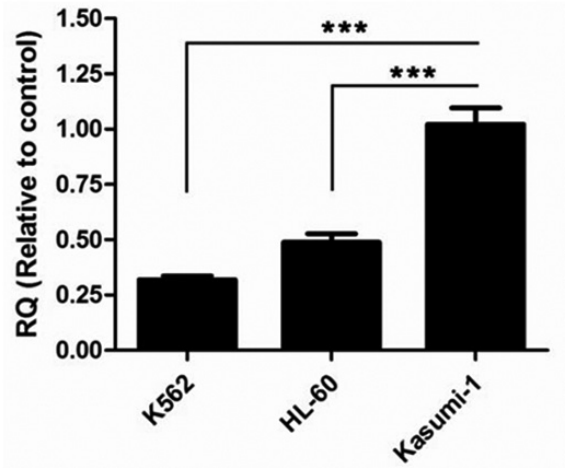

Figure 1. Overexpression of APP in Kasumi-1 cell line with AML1/ETO positive. (A) Protein expression levels of APP in three AML cell lines were analyzed by western blotting. The expression levels of GAPDH in the lysates served as the loading control. (B) The relative mRNA levels of APP were detected by $\mathrm{qRT}-\mathrm{PCR}$ and then analyzed with $2^{-\mathrm{ACt}}$ method. Bar graphs represent the mean $\pm \mathrm{SD}$ of at least three independent experiments. ${ }^{(* *} P<0.001$ vs Kasumi-1, One-Way ANOVA).

A

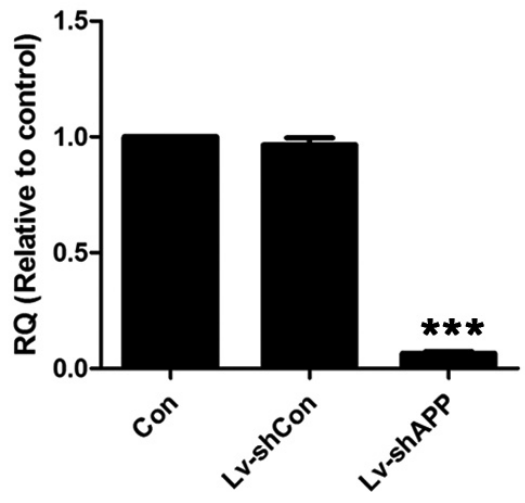

B

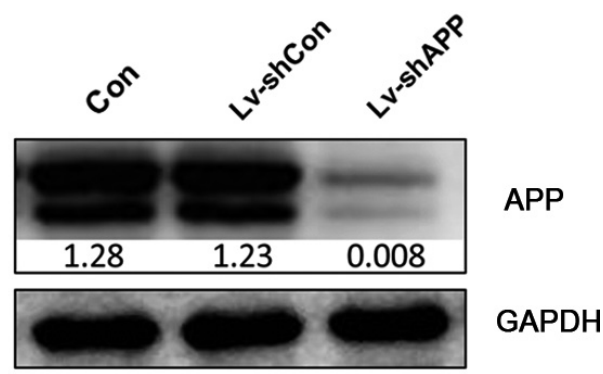

Figure 2. Stable knockdown of APP in Kasumi-1 cells by lentivirus-based RNAi. (A) Quantification of mRNA expression levels relative to $\beta$-Actin was analyzed by $q R T$-PCR. The data shown are the mean \pm SD of at least three independent experiments $\left({ }^{* * *} P<0.001\right.$ vs Con). (B) Protein levels of APP were analyzed by western blotting. GAPDH was used as a loading control.

in the bottom medium were fixed with $4 \%$ paraformaldehyde and quantified after staining with hematoxylin.

Analysis of PS treatment on APP expression in Kasumi-1 cells. Kasumi- 1 cells were seeded into 96 -well plates with $5 \times 10^{3}$ in $100 \mu \mathrm{L}$ complete medium per well. After treatment with PS (Selleck, Houston, Texas, USA) at different concentrations for different time points (24, 48, and 72 hours), CCK-8 reagent was used to analyze the cell survival rate of PS on Kasumi-1 cells. After designated treatments with PS for 48 hours, the expression levels of APP was analyzed by western blotting.

Effects of PS treatment on apoptosis and differentiation of Kasumi-1 cells. Kasumi-1 cells were cultured in six-well plates at a density of $5 \times 10^{5}$ cells per well and were exposed to PS at 10, $20\left(\mathrm{IC}_{50}\right.$ value) and $40 \mathrm{nM}$ for 48 hours. Untreated or drug-treated cells were stained with Annexin V-FITC and PI (BD Biosciences, New Jersey, USA), and the percentage of apoptotic cells was analyzed by flow cytometry. After been treated with PS at $5 \mathrm{nM}$ and $10 \mathrm{nM}$ for 10 days, drug-treated and untreated Kasumi-1cells were collected and detected the percentage of differentiated cells with CD11b-FITC staining(BD Biosciences, USA) by flow cytometry. Besides, the cellular morphology were assessed by Wright staining.

Stastistical analysis. Statistical analyses were performed with SPSS 16.0 software. All results are presented as mean \pm SD from at least three independent experiments. The data were evaluated by one-way ANOVA. A $P$-value of less than 0.05 was considered to be statistically significant.

\section{Results}

APP is overexpressed in Kasumi-1 cells with AML1/ETO positive. To investigate the function of APP in vitro, we evaluated APP expression levels in three AML cell lines, K562, HL60 and Kasumi-1. As shown in Figure 1A and B, the protein and 
A

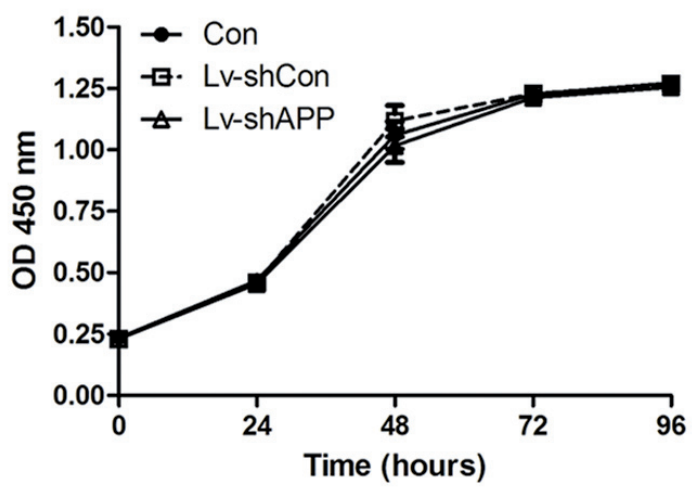

B

a

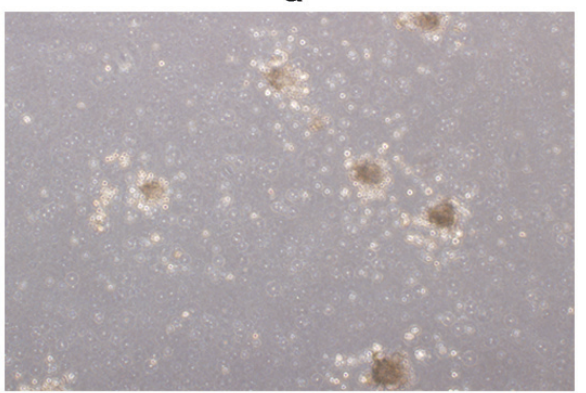

C

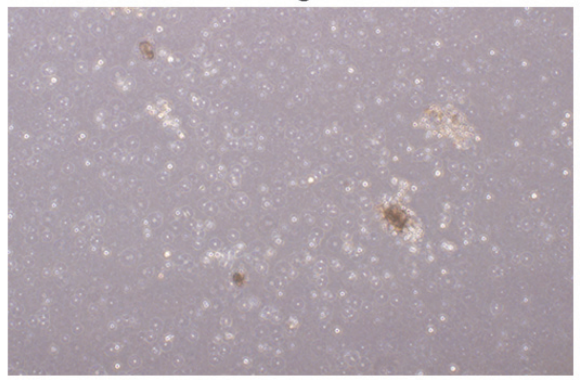

b

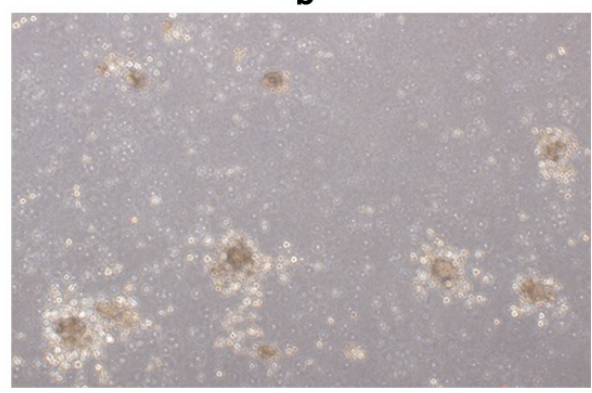

d

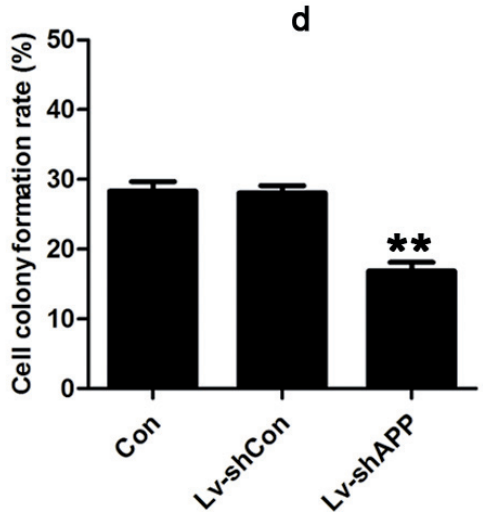

Figure 3. APP knockdown reduces clonogenetic survival of Kasumi-1 cells. (A) CCK-8 reagent was utilized to measure the inhibition of cell proliferation following APP knockdown. (B) After APP knockdown in Kasumi-1 cells, the colony growth in semi-sold media were assessed after 14 days. Each bar represents the mean \pm SD of three or more independent experiments $\left({ }^{*} P<0.01\right.$ vs Con).

mRNA expression levels of APP in Kasumi-1 was significantly higher than that in K562 and HL60 cell lines $(P<0.001)$. As a result, Kaumi-1 cell line was used to explore the roles of APP in AML1/ETO-positive leukemia cells.

Lentivirus-mediated shRNA decreased APP expression in Kasumi-1 cells. We first decreased expression levels of APP using a lentiviral-based shRNA in Kasumi-1 cells. As shown in Figure 1C, compared to untreated cells (Con) and negative shRNA treated cells (Lv-shCon), the relative mRNA levels of APP were dramatically reduced in Lv-shAPP infected cells $(P<0.001)$. No significant difference was observed between Con group and Lv-shCon group. Western blotting analysis also verified the obvious down-regulation of APP expression in Kasumi-1 cells at protein levels (Figure 2B).

APP knockdown markedly reduces clonal growth of Kasumi-1 cells. Next, we investigated the effect of APP knockdown on cell viability and clonal growth of Kasumi-1. As shown in Figure 3A, in comparison with untreated and $\mathrm{Lv}$-shCon infected cells, depletion of APP gene decreased cell viability slightly. However, no statistical significance was found in these differences $(P>0.05)$. Notably, APP knockdown dramatically reduced the rate of colony-formation of Kasumi- 1 cells when compared with con group $(28.30 \pm 2.37 \%$ vs $16.83 \pm 2.21 \%, P<0.01$, Figure $3 \mathrm{~B})$. 
A

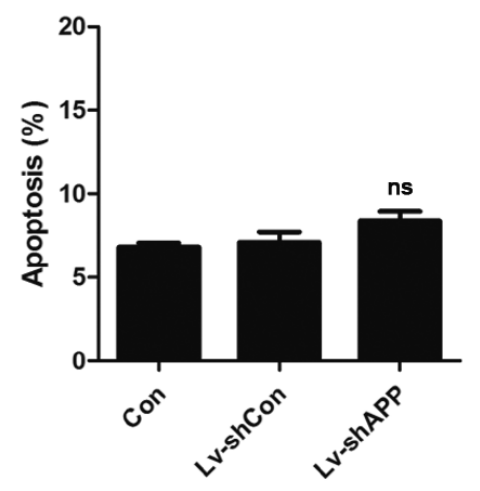

C

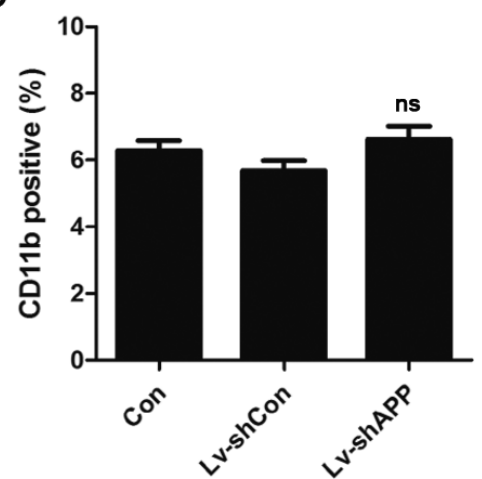

B
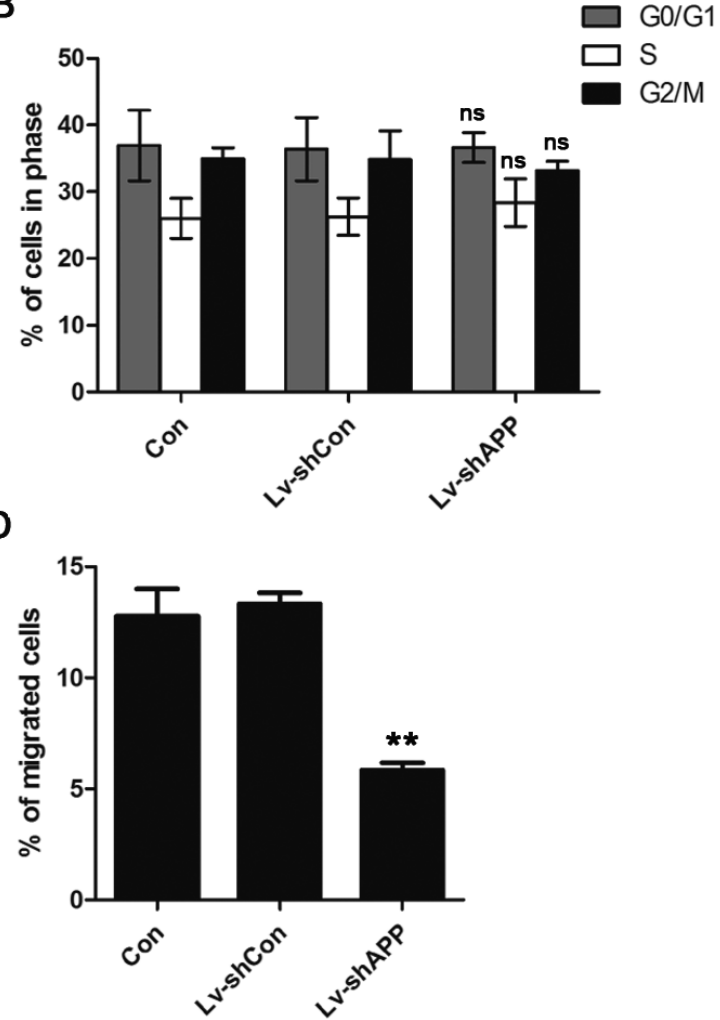

Figure 4. APP knockdown suppresses the migration of Kasumi-1 cells. (A), (B) and (C) Flow cytometry analysis of cell apoptosis, cell cycle and differentiation showed no difference after APP knockdown in Kasumi-1 cells. (D) Cell migration was detected by transwell assay. APP knockdown decreased cell migration significantly. ${ }^{* *} P<0.01$ vs Con, ns: non-significance vs Con).

APP knockdown mainly impairs migration ability of Kasumi-1 cells. We next determined the effect of APP knockdown on cell apoptosis, cell-cycle, differentiation and migration of Kasumi-1 cells. As shown in Figure 4A, B and C, When compared with Kasumi-1 cells in con and Lv-shCon groups, APP knockdown had little effect on cell apoptosis, cell-cycle distribution and cell differentiation $(P>0.05)$. It was worth noting that APP knockdown dramatically impaired the ability of cell migration when compared with control group $(P<0.01)$ (Figure 4D).

3.5. PS treatment depletes protein levels of APP and induces cell apoptosis and differentiation of Kasumi-1 cells

Figure 5A showed that the suppressive effect of PS on Kasumi-1 cells was proved to be a concentration- and timedependent manner. The concentration of PS that induced inhibition in $50 \%$ of the treated cell population (IC50 value) was $20 \mathrm{nM}$. We next investigated the effect of PS treatment on expression of APP in Kasumi-1 cells. Inspiringly, we found that the protein levels of APP in Kasumi-1 cells was depleted after treatment with PS for 48 hours with increasing concentrations (Figure 5B). Furthermore, the total apoptosis rate was increased in Kasumi-1 cells treated with increased PS concentrations for 48 hours, especially those of late (annexin- $\mathrm{V}$ positive; PI positive) apoptotic cells. Meanwhile, the number of necrotic cells also significantly increased with treatment of PS at concentrations of $20 \mathrm{nM}$ and $40 \mathrm{nM}$, which was expected since due to the cytotoxic effects of PS (Figure 5C). In addition, treatment with PS at relatively low concentrations of $5 \mathrm{nM}$ and $10 \mathrm{nM}$ for 10 days increased the percentage of CD11b-positive cells from $5.54 \%$ to $7.38 \%$ and $15.62 \%$, respectively.

\section{Discussion}

In the present study, we demonstrated that APP knockdown in Kasumi- 1 cells mainly impairs the ability of cell proliferation and migration rather than induces apoptosis, arrests cellcycles or induces cell differentiation. In addition, treatment with PS depleted the expression of APP in a dose-dependent manner at 48 hours, and a high concentration of PS promotes apoptosis of Kasumi-1 cell, whereas a low concentration of PS induces cell differentiation. These results suggest that increased expression of APP promotes proliferation and migration of Kasumi-1 cells, and PS is confirmed as an effective drug against AML1/ETO-positive leukemia cells by depleting expression levels of APP, promoting cell apoptosis and inducing cell differentiation. 
A

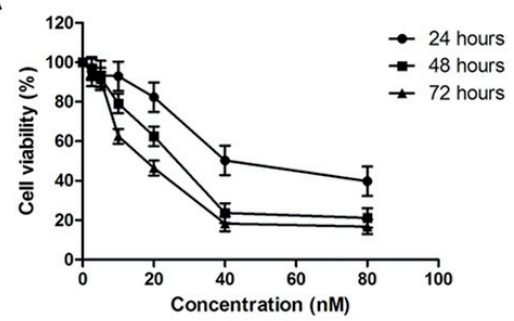

B

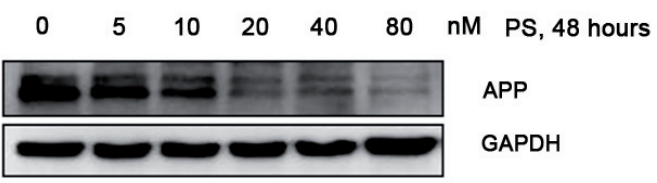

C
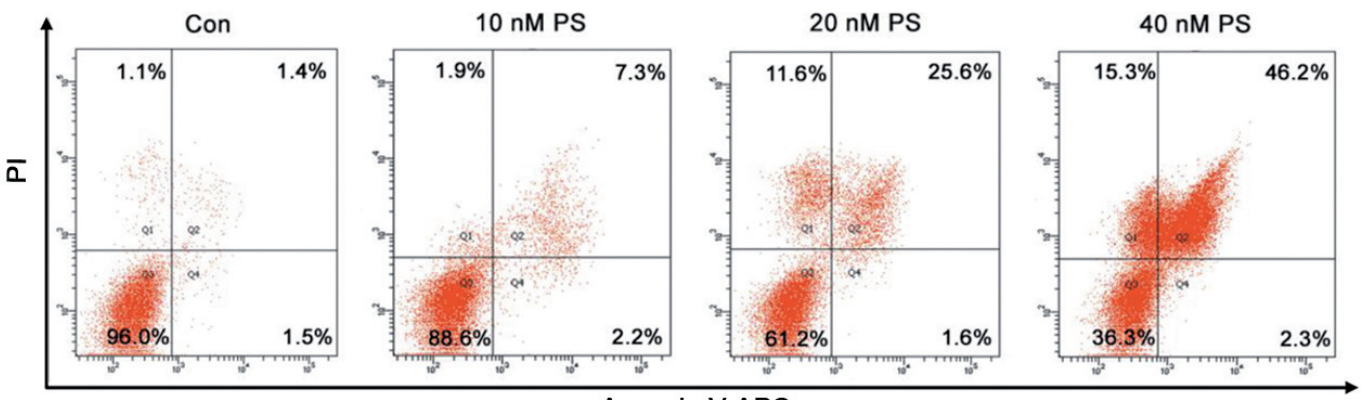

Annexin V-APC

\section{D}

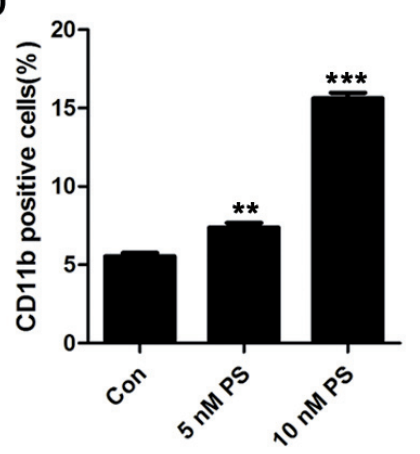

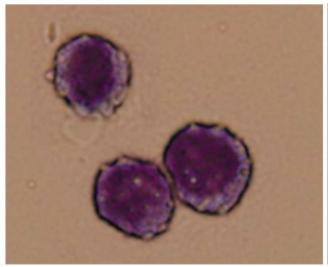

Con

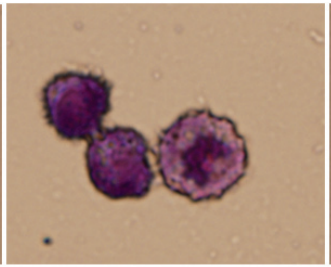

5 nM PS

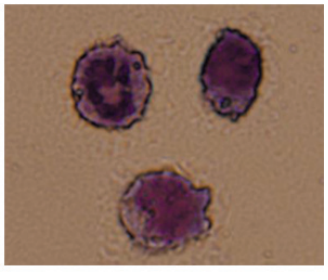

$10 \mathrm{nM} P \mathrm{~S}$

Figure 5. Treatment with PS depletes APP expression levels, induces cell apoptosis and differentiation of Kasumi-1 cells. (A) CCK-8 was utilized to measure the inhibition of cell proliferation following PS treatment. The half inhibitory concentration (IC $\mathrm{I}_{50}$ ) for 48 hours was $20 \mathrm{nM}$. (B) PS treatment depleted expression levels of APP in a dose-dependent manner. (C) After treatment with 10, 20 and $40 \mathrm{nM}$ concentrations of PS for 48 hours, flow cytometry analysis was carried out on Kasumi- 1 treated and untreated cells. (D) Kasumi-1 cells were treated with PS at low concentrations at 5 nM and $10 \mathrm{nM}$ for 10 days. After this, the percentages of $\mathrm{CD} 11 \mathrm{~b}^{+}$cells were determined by flow cytometry, and the cellular morphology were assessed by Wright staining. ( ${ }^{* *} P<0.01$ vs Con, ${ }^{* * *} P<0.001$ vs Con).

Recent work have identified that increased expression of APP is assumed to be a promoting factor for malignant tumors. In the human colon carcinoma cell line SW837, inhibition of APP expression using an antisense RNA strategy markedly suppresses proliferative potential and colonyforming efficiency compared with the mock-transfected clones in vitro[18]. A research of APP on prostate cancer indicated that APP promotes the growth of prostate cancer cells, and knockdown of APP in mice represses tumor growth[19]. Increased APP expression is also found in papillary thyroid carcinoma samples compared with adjacent non-tumor thyroid tissue by immunohistochemistry, and high APP scores is correlated with large tumor size, extracapsular invasion and lymph node metastasis[20]. Unlike solid tumors, APP is only overexpressed in bone marrow mononuclear cells samples of AML1/ETO-positive AML compared to non-malignant hematology[21]. Similarly, the APP expression is significantly higher in AML with abnormal chromosome 21 compared with normal cytogenetics using oligonucleotide arrays[12]. It seemed that increased APP expression is closely tied with $t(8 ; 21)$ translocation in leukemia. In this study, we found that APP knockdown dramatically impaired the ability of migration, while inhibiting cell proliferation very little. The results demonstrated that the role of APP in AML1/ETO-positive leukemia cells is mainly mediating cell migration, which is different from the roles of APP in solid tumor cells. A recent published research found that APP-overexpression LNCap prostate cell line exhibits enhanced migration in comparison to control cells, and several metalloproteinase genes, such as ADAM10 
and ADAM17, are downregulated in siAPP-treated cells as compared with control cells by microarray analysis[22]. As a result, APP is closely related to promoting proliferation and migration of different tumor cells.

Overexpression of APP has been confirmed as a poor prognostic marker in several human malignancies, which may serve as a potential therapeutic target. However, the specific ligands to APP remain elusive, and antagonists of APP have not been reported. The gama- secretase inhibitors can reduce the generation of $A \beta$ from APP, wherase do not decrease the full-length APP that acting as a membrane receptor. Additionally, the safety and feasibility of lentivirus-mediated RNAi method are still controversial. Therefore, finding drugs that can inhibit expression of APP may be feasible options for tumor therapy. In view of PS affecting multiple pathways and genes involved in apoptosis, cell cycle arrest and angiogenesis, its greatest potential is very likely to inhibit expression of APP. In this paper, our findings indicated that PS treatment effectively decreases the protein levels of APP in Kasumi-1 cells. In addition, a high concentration of PS mainly promotes apoptosis of Kasumi-1 cells, whereas a low concentration of PS induces cell differentiation.

In summary, our results demonstrated that APP is involved in promoting proliferation and migration of AML1/ ETO-positive leukemia cells. The vitro study on Kasumi-1 cells confirms that PS can deplete the expression of APP, induce cell apoptosis and differentiation, which provides a rational clinic protocol to treat patients with AML1/ETOpositive AML.

Acknowledgements: We thank Dr Zhengshan Yi (Hematology Laboratory of Nanfang Hospital) for technical assistance. We are also grateful to Dr Zijie Long for providing the Kasumi-1 cell line. This work was supported by Guangzhou Science and Technology Plan Projects (No. 2013J4100109) and the Specialized Research Foud for the Doctoral Program of Higher Education (No. 20124433110001).

\section{References}

[1] GRITSAEV SV, MARTYNKEVICH IS, ZIUZGIN IS, KARIAGINA EV, MARTYNENKO LS et al. Heterogeneity of acute myeloid leukemia with the translocation $\mathrm{t}(8 ; 21)$ (q22; q22). Ter Arkh 2014; 86: 45-52.

[2] NUMATA A, FUJIMAKI K, AOSHIMA T, ONIZUKA M, HAGIHARA $M$ et al. Retrospective analysis of treatment outcomes in 70 patients with $\mathrm{t}(8 ; 21)$ acute myeloid leukemia. Rinsho Ketsueki 2012; 53: 698-704.

[3] SOBA P, EGGERT S, WAGNER K, ZENTGRAF H, SIEHL $\mathrm{K}$ et al. Homo- and heterodimerization of APP family members promotes intercellular adhesion. EMBO J 2005; 24: 3624-3634. http://dx.doi.org/10.1038/sj.emboj.7600824

[4] BILLNITZER AJ, BARSKAYA I, YIN C, PEREZ RG. APP independent and dependent effects on neurite outgrowth are modulated by the receptor associated protein (RAP). J Neurochem 2013; 124: 123-132. http://dx.doi.org/10.1111/jnc.12051
[5] HOE HS, LEE KJ, CARNEY RS, LEE J, MARKOVA A et al. Interaction of reelin with amyloid precursor protein promotes neurite outgrowth. J Neurosci 2009; 29: 7459-7473. http:// dx.doi.org/10.1523/JNEUROSCI.4872-08.2009

[6] YOUNG-PEARSE TL, CHEN AC, CHANG R, MARQUEZ C, SELKOE DJ. Secreted APP regulates the function of full-length APP in neurite outgrowth through interaction with integrin beta 1 . Neural Dev 2008. 3: 15. http://dx.doi. org/10.1186/1749-8104-3-15

[7] WANG Z, WANG B, YANG L, GUO Q, AITHMITTI N et al. Presynaptic and postsynaptic interaction of the amyloid precursor protein promotes peripheral and central synaptogenesis, J Neurosci 2009; 29: 10788-10801. http://dx.doi. org/10.1523/JNEUROSCI.2132-09.2009

[8] KO SY, LIN SC, CHANG KW, WONG YK, LIU CJ et al. Increased expression of amyloid precursor protein in oral squamous cell carcinoma. Int J Cancer 2004; 111: 727-732. http://dx.doi.org/10.1002/ijc.20328

[9] HANSEL DE, RAHMAN A, WEHNER S, HERZOG V, YEO CJ et al. Increased expression and processing of the Alzheimer amyloid precursor protein in pancreatic cancer may influence cellular proliferation. Cancer Res 2003; 63: 7032-7037.

[10] HAVEN CJ, HOWELL VM, EILERS PH, DUNNE R, TAKAHASHI $\mathrm{M}$ et al. Gene expression of parathyroid tumors: molecular subclassification and identification of the potential malignant phenotype. Cancer Res 2004; 64: 7405-7411. http:// dx.doi.org/10.1158/0008-5472.CAN-04-2063

[11] TAKAGI K, ITO S, MIYAZAKI T, MIKI Y, SHIBAHARA Y et al. Amyloid precursor protein in human breast cancer: an androgen-induced gene associated with cell proliferation. Cancer Sci 2013: 1532-1538. http://dx.doi.org/10.1111/cas.12239

[12] BALDUS CD, LIYANARACHCHI S, MRÓZEK K, AUER $\mathrm{H}$, TANNER SM et al. Acute myeloid leukemia with complex karyotypes and abnormal chromosome 21: Amplification discloses overexpression of APP, ETS2, and ERG genes. Proc Natl Acad Sci USA 2004; 101: 3915-3920. http://dx.doi. org/10.1073/pnas.0400272101

[13] JIANG L, YU G, MENG W, WANG Z, MENG F et al. Overexpression of amyloid precursor protein in acute myeloid leukemia enhances extramedullary infiltration by MMP-2. Tumour Biol 2013; 34: 629-636. http://dx.doi.org/10.1007/ s13277-012-0589-7

[14] FISKUS W, WANG Y, SREEKUMAR A, BUCKLEY KM, $\mathrm{SHI} \mathrm{H}$ et al. Combined epigenetic therapy with the histone methyltransferase EZH2 inhibitor 3-deazaneplanocin A and the histone deacetylase inhibitor panobinostat against human AML cells. Blood 2009; 114: 2733-2743. http://dx.doi. org/10.1182/blood-2009-03-213496

[15] FISKUS W, BUCKLEY K, RAO R, MANDAWAT A, YANG $\mathrm{Y}$ et al. Panobinostat treatment depletes EZH2 and DNMT1 levels and enhances decitabine mediated de-repression of JunB and loss of survival of human acute leukemia cells. Cancer Biol Ther 2009; 8: 939-950. http://dx.doi.org/10.4161/ cbt.8.10.8213

[16] TAN P, WEI A, MITHRAPRABHU S, CUMMINGS N, LIU $\mathrm{HB}$ et al. Dual epigenetic targeting with panobinostat and 
azacitidine in acute myeloid leukemia and high-risk myelodysplastic syndrome. Blood Cancer J 2014; 4: e170. http:// dx.doi.org/10.1038/bcj.2013.68

[17] PIETSCHMANN K, BOLCK HA, BUCHWALD M, SPIELBERG S, POLZER H et al. Breakdown of the FLT3-ITD/ STAT5 axis and synergistic apoptosis induction by the histone deacetylase inhibitor panobinostat and FLT3-specific inhibitors. Mol Cancer Ther 2012; 11: 2373-2383. http:// dx.doi.org/10.1158/1535-7163.MCT-12-0129

[18] MENG JY, KATAOKA H, ITOH H, KOONO M. Amyloid beta protein precursor is involved in the growth of human colon carcinoma cell in vitro and in vivo. Int J Cancer 2001; 92: 31-39. http://dx.doi.org/10.1002/1097-0215(200102)9999:9999<::AID-IJC1155>3.0.CO;2-H

[19] TAKAYAMA K, TSUTSUMI S, SUZUKI T, HORIE-INOUE $\mathrm{K}$, IKEDA $\mathrm{K}$ et al. Amyloid precursor protein is a primary androgen target gene that promotes prostate cancer growth. Cancer Res 2009; 69: 137-142. http://dx.doi.org/10.1158/00085472.CAN-08-3633

[20] YANG Z, FAN Y, DENG Z, WU B, ZHENG Q. Amyloid precursor protein as a potential marker of malignancy and prognosis in papillary thyroid carcinoma, Oncol Lett 2012; 3: 1227-1230.

[21] WANG W, MENG FY, HUANG ZF, HUANG M, LIU LX. Expression and role of amyloid precrusor protein gene in acute myeloid leukemia, Zhonghua Xue Ye Xue Za Zhi 2010; 31: 309-314.

[22] MIYAZAKI T, IKEDA K, HORIE-INOUE K, INOUE S. Amyloid precursor protein regulates migration and metalloproteinase gene expression in prostate cancer cells. Biochem Biophys Res Commun 2014; 452: 828-833. http://dx.doi. org/10.1016/j.bbrc.2014.09.010 